\title{
Load capacity of worm gear transmission from aspect of maximal use of available resources
}

\author{
Aleksandar Miltenović ${ }^{1, *}$, Milan Banić ${ }^{1}$, and Đorđe Miltenović ${ }^{2}$ \\ ${ }^{1}$ University of Niš, Faculty of Mechanical Engineering, 14 A. Medvedeva, 18000 Niš, Serbia \\ ${ }^{2}$ The College of Textile, V. Pušmana, 16000 Leskovac, Serbia
}

\begin{abstract}
Worm gear transmission has number of advantages over the other types of transmission (high transmission ratio, compact design, high load capacity, vibration damping, reliability, etc.) and thus is widely used as drives in application with short-term load and for the transmission of movement. Previous studies in this area show that in their work can occur a larger number of damage forms that are limiting the load capacity of this drives and that can be identified based on the condition of working surfaces. The occurrence of any limit state represents the termination of work function, no matter that resources for other limit states are not reached. Theoretically, the best use of transmission would be if the load capacity for all limit states has uniform use. The paper is focusing a detailed analysis of the load carrying capacity of worm gear transmission from aspect of the available resources.
\end{abstract}

\section{Introduction}

Worm gears have a wide range of applications, particularly in the short-term drive because of their significant advantages. Applications of worm gear drives such as machine tools, transport equipment and vehicles are primarily linked to the transfer of power, as well as fine and precision devices for the transfer of movement. The most important advantage is their large transmission ratio, which in one stage can be achieved in the range of $i=5$ to $i=$ 70. In this way, it is possible to achieve a very large area of output speeds.

Contact between tooth flans is a line and depending on gear parameters contact can be on number of teeth (usually $2 \ldots 4$ ). Because of the contact line between flanks occurs relatively large sliding. Meshing is realized with oil layer between the flanks which decreases the internal dynamic forces, with vibration damping [1-2]. This benefit primarily relates to worm gear sets with greater efficiency [3].

High slip between flanks of worm and worm gear leads to high local surface pressure, which requires the use of materials worm pairs that are resistant to scuffing damage form [4]. A possible solution for this is a combination of dissimilar soft and hard material of worm gear pair. Therefore, in modern structural solutions usually worm gear made of tin bronze a worm tempered and brushed steel. The disadvantage of this solution is low strength and high price of the production of worm gear [5].

\footnotetext{
* Corresponding author: amiltenovic@yahoo.com
} 
This paper shows that the small changes in parameters of worm gear drives can lead to the significant savings which is not the case in other drives such as drives with spur, helical or bevel gears. Therefore, this is one more advantage of worm gear drives which product development engineers are often not aware.

\section{Load Capacity and Available Resources of Worm Gear Transmission}

Criteria for load capacity of worm gear drive are torque on worm gear or the output torque, which is directly coupled to the driven machine. The values of the output torque are limiting boundary conditions that can occur during operation of the transmission. The most common limit states are:

- destruction of tooth flanks due to pitting,

- wear of tooth flanks,

- fracture of the worm gear tooth at the root,

- heating and heat distortion stability of transmission,

- scuffing.

For the analysis of load capacity of worm gear drive is considered a family of transmission $a=63, a=100$ and $a=250$, whose characteristics are given in Table 1 . Calculation of load capacity of the worm gear transmission according to DIN 3996 [6] regarding to wear, pitting, teeth fracture and the thermal stability. The critical layer thickness is estimated by thickness of wear layer on the tip of tooth.

Table 1. Transmission data for $a=63 \mathrm{~mm} ; a=100 \mathrm{~mm} ; a=250 \mathrm{~mm}$.

\begin{tabular}{|c|c|c|c|c|c|c|c|}
\hline \multirow{7}{*}{$\begin{array}{c}ई \\
\vdots \\
\approx \\
\| \\
0\end{array}$} & Transmission ratio & $\boldsymbol{u}$ & & 9.75 & 19.5 & 29 & 39 \\
\hline & Number of teeth of worm & $z_{1}$ & & 4 & 2 & 1 & 1 \\
\hline & Number of teeth of worm gear & $z_{2}$ & & 39 & 39 & 29 & 39 \\
\hline & Axial module & $m_{x}$ & $\mathrm{~mm}$ & 2.5 & 2.5 & 3.15 & 2.5 \\
\hline & Operative diameter of worm & $d_{m l}$ & $\mathrm{~mm}$ & 26.5 & 26.5 & 33.5 & 26.5 \\
\hline & Root diameter of worm & $d_{f 1}$ & $\mathrm{~mm}$ & 20.5 & 20.5 & 25.94 & 20.5 \\
\hline & Root diameter of worm gear & $d_{f 2}$ & $\mathrm{~mm}$ & 93.5 & 93.5 & 84.94 & 93.5 \\
\hline \multirow{7}{*}{ 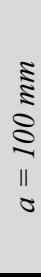 } & Transmission ratio & $u$ & & 10.33 & 20.5 & 29 & 40 \\
\hline & Number of teeth of worm & $z_{1}$ & & 3 & 2 & 1 & 1 \\
\hline & Number of teeth of worm gear & $z_{2}$ & & 31 & 41 & 29 & 40 \\
\hline & Axial module & $m_{x}$ & $\mathrm{~mm}$ & 5 & 4 & 5 & 4 \\
\hline & Operative diameter of worm & $d_{m l}$ & $\mathrm{~mm}$ & 45 & 36 & 53.175 & 40 \\
\hline & Root diameter of worm & $d_{f 1}$ & $\mathrm{~mm}$ & 33 & 26.4 & 41.175 & 30.4 \\
\hline & Root diameter of worm gear & $d_{f 2}$ & $\mathrm{~mm}$ & 143 & 154.4 & 134.82 & 150.4 \\
\hline \multirow{7}{*}{ 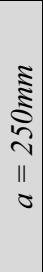 } & Transmission ratio & $u$ & & 10 & 20 & 31 & 40 \\
\hline & Number of teeth of worm & $z_{1}$ & & 4 & 2 & 1 & 1 \\
\hline & Number of teeth of worm gear & $z_{2}$ & & 40 & 40 & 31 & 40 \\
\hline & Axial module & $m_{x}$ & $\mathrm{~mm}$ & 10 & 10 & 12.5 & 10 \\
\hline & Operative diameter of worm & $d_{m l}$ & $\mathrm{~mm}$ & 95 & 95 & 112 & 95 \\
\hline & Root diameter of worm & $d_{f 1}$ & $\mathrm{~mm}$ & 71 & 71 & 82 & 71 \\
\hline & Root diameter of worm gear & $d_{f 2}$ & $\mathrm{~mm}$ & 381 & 381 & 358 & 381 \\
\hline
\end{tabular}

For comprehensive review of load capacity of worm gear drive according to different criteria are varied the following parameters (Table 1):

- Axial distance ( $a=63 \mathrm{~mm} ; a=100 \mathrm{~mm} ; a=250 \mathrm{~mm})$,

- Transmission ratio $(i=10 ; i=20 ; i=30 ; i=40)$, 
- Worm speed $\left(n_{l}=200 \min ^{-1} ; n_{l}=500 \min ^{-1} ; n_{l}=1000 \mathrm{~min}^{-1} ; n_{l}=1500 \mathrm{~min}^{-1}\right.$; $\left.n_{l}=2000 \mathrm{~min}^{-1}\right)$,

- Material of worm gear (CuSn12-C-GZ; CuAl10Fe5Ni5-C-GZ; EN-GJS-400-15)

- Oil (mineral, synthetic),

- Lubrication (immersed, injection),

- Lifetime $L_{h}=10000 \mathrm{~h}$.
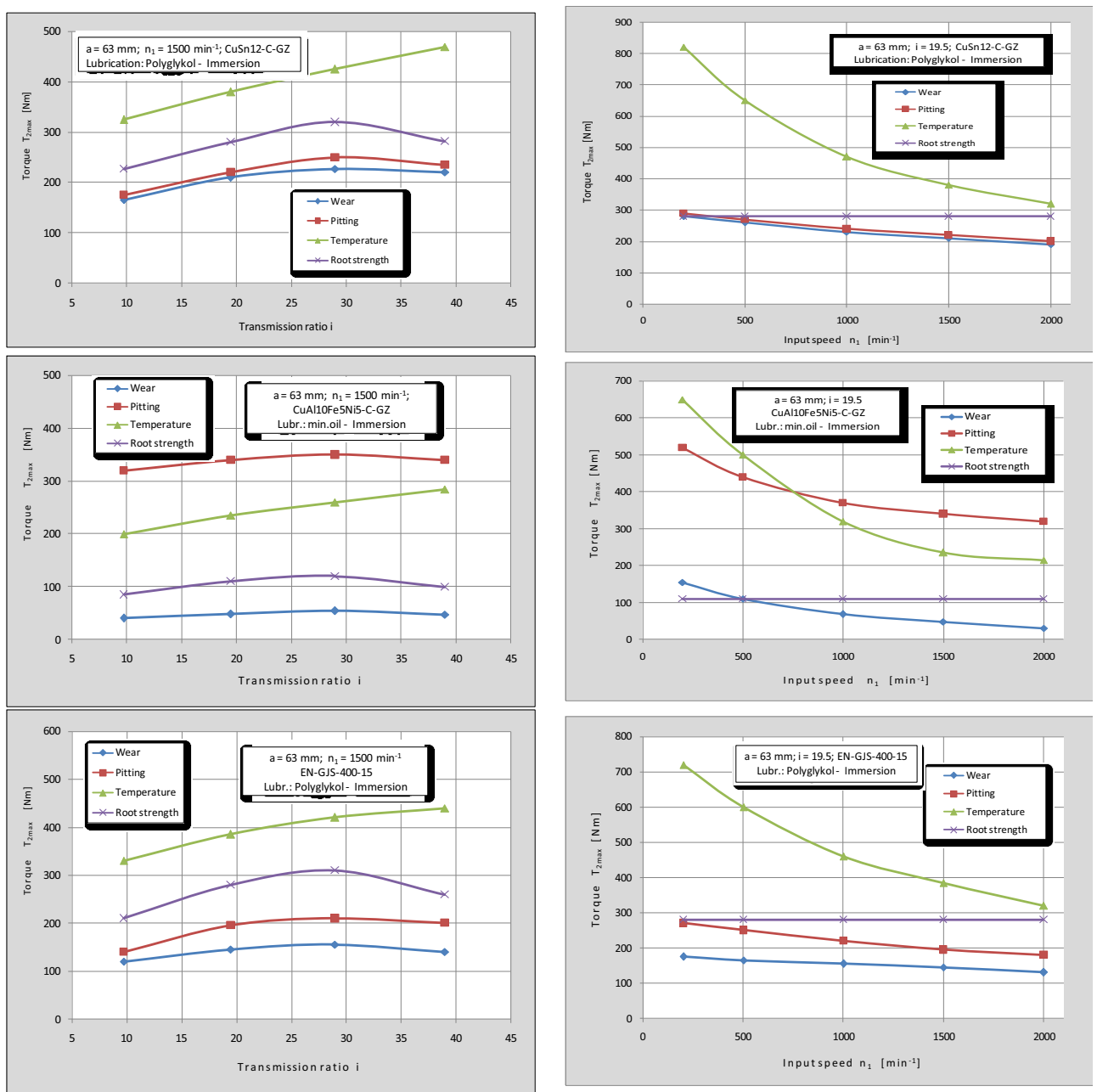

Fig. 1. Load capacity of drive with $\mathrm{a}=63 \mathrm{~mm}$ for different transmission ratio, speeds and materials of worm gears.

\subsection{Transmission a-63}

The calculation results of the load capacity of the drive a-63 $(a=63 \mathrm{~mm})$ are shown in figure1.

For drive a-63 with worm made of alloy steel and worm gear from tin bronze CuSn12C-GZ with the varying transmission ratio for constant speeds $n_{l}=1500 \mathrm{~min}^{-1}$ optimum load capacity is obtained for the area of transmission ratio $i=20-30$. For the transmission ratio 
$i=19.5$ and vary speeds respectively sliding speed, nearly all criteria obtained uniform load capacity, which is good from the aspect of transmission resources.

Transmission a-63 with worm made of alloy steel and worm gear of Al-bronze $\mathrm{CuA} 110 \mathrm{Fe} 5 \mathrm{Ni} 5 \mathrm{C}-\mathrm{GZ}$ with varying transmission ratio and at varying speeds according to all criteria, the calculation results not uniform load capacity.

Transmission a-63 with worm made of alloy steel and worm gear of ductile iron ENGJS 400-15 at varying transmission ratio for constant speeds $n_{l}=1500 \mathrm{~min}^{-1}$ optimum load capacity is obtained for the area of transmission ratio $i=20-30$. Even with varying transmission ratio and at varying speeds on all the criteria of the calculation results in good uniformity load capacity.
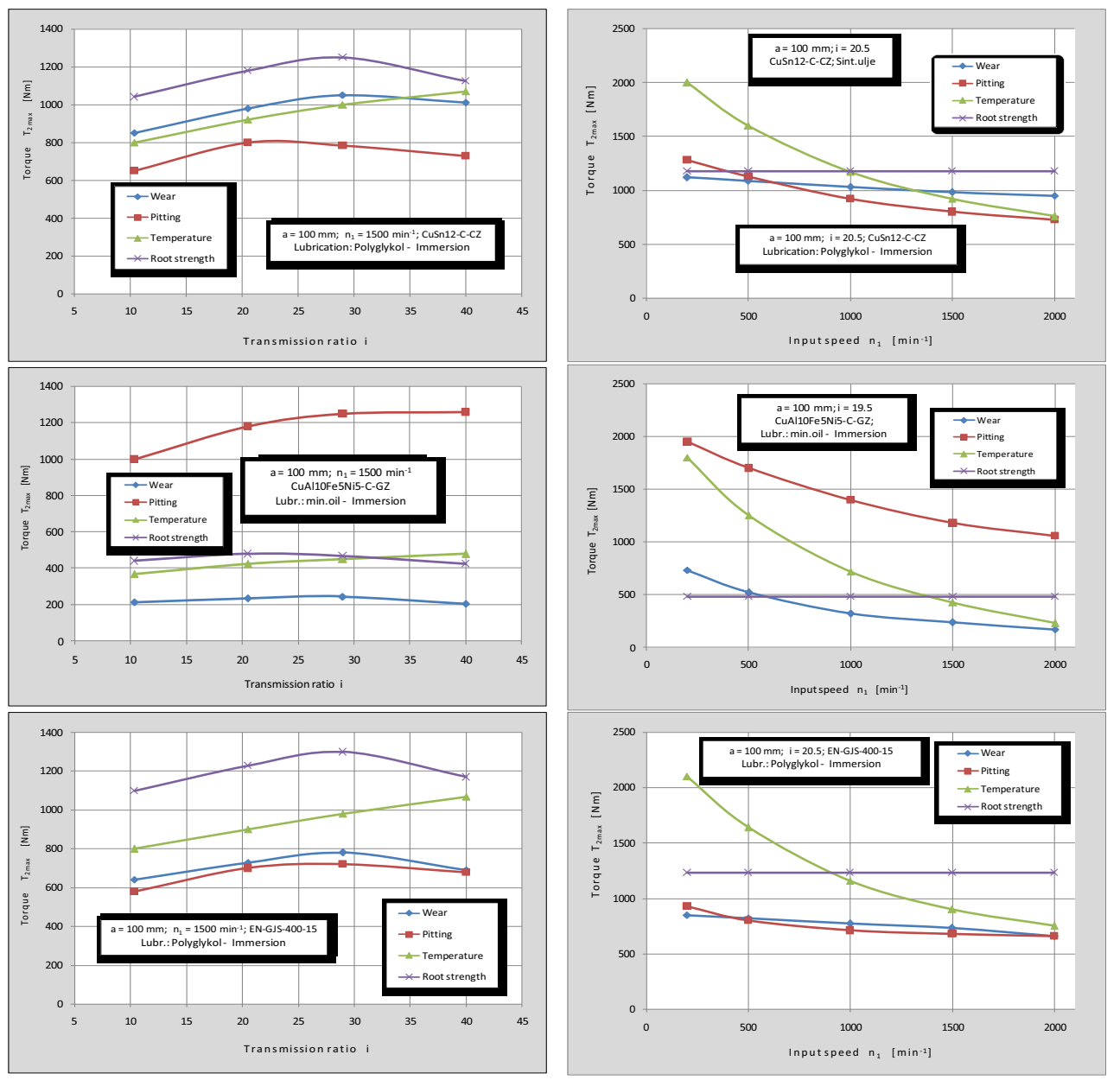

Fig. 2. Load capacity of drive with $a=100 \mathrm{~mm}$ for different transmission ratio, speeds and materials of worm gears.

\subsection{Transmission a-100}

Calculation of load capacity of drive a-100 $(a=100 \mathrm{~mm})$ was performed in a similar manner as the calculation of load capacity of the drive a-63. The calculation results are given in the load capacity at figure 2 . 
Drive a-100 with worm made of alloy steel and worm gear from tin bronze CuSn12-CGZ can be seen that with the varying transmission ratio for constant speeds $n_{l}=1500 \mathrm{~min}^{-1}$ optimum load capacity is obtained for the area of transmission ratio $i=20-30$. For the gear ratio $i=20.5$ and vary speeds regarding sliding speed nearly all criteria, the calculation results with balanced load capacity, which is not the case with varying transmission ratio.
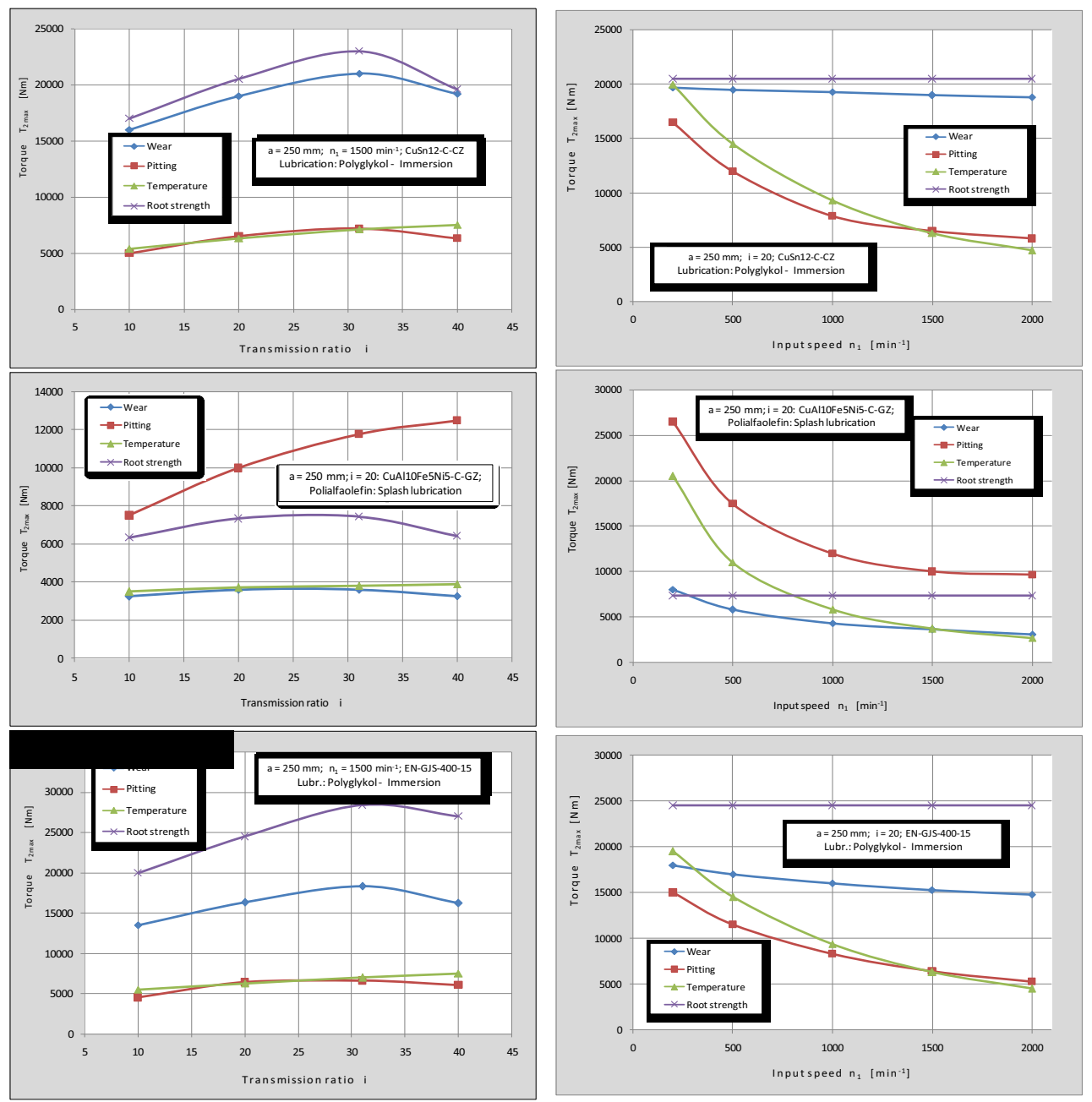

Fig. 3. Load capacity of drive with $a=250 \mathrm{~mm}$ for different transmission ratio, speeds and materials of worm gears.

When drive a-100 with a worm made of alloy steel and worm gear of Al-bronze $\mathrm{CuAl10Fe} 5 \mathrm{Ni} 5 \mathrm{C}-\mathrm{GZ}$ can be seen that with varying transmission ratio and at varying speeds according to all criteria, the calculation results are showing the not uniform load capacity. Consequently, the resources available of transmission are only partially used.

For worm drive a-100 with a worm made of alloy steel and worm gear made of ductile iron EN-GJS-400-15 can be seen that with the varying transmission ratio for constant speeds $n_{l}=1500 \mathrm{~min}^{-1}$ optimum load capacity is obtained for the area of transmission ratio $i=20-30$. 
Table 2. Limitation of load capacities of transmission.

\begin{tabular}{|c|c|c|c|c|c|}
\hline $\begin{array}{l}\mathbf{N} \\
\mathbf{0}\end{array}$ & $\begin{array}{l}\text { Worm } \\
\text { gear } \\
\text { material }\end{array}$ & $\begin{array}{l}\text { Transmission } \\
\text { ratio/ Speed }\end{array}$ & $a=63 \mathrm{~mm}$ & $a=100 \mathrm{~mm}$ & $a=250 \mathrm{~mm}$ \\
\hline 1 & \multirow{9}{*}{ Tin bronze } & $i=10$ & \multirow{4}{*}{ H (B); UN } & \multirow{4}{*}{ B; UN } & \multirow{3}{*}{$\mathbf{T}, \mathbf{B}, \mathrm{NUN}$} \\
\hline 2 & & $i=20$ & & & \\
\hline 3 & & $i=30$ & & & \\
\hline 4 & & $i=40$ & & & B, NUN \\
\hline 5 & & $n_{l}=200 \mathrm{~min}^{-1}$ & \multirow{5}{*}{$\mathbf{H}, \mathbf{B}, \mathrm{UN}$} & \multirow{2}{*}{ H; UN } & \multirow{3}{*}{ B, NUN } \\
\hline 6 & & $n_{l}=500 \mathrm{~min}^{-1}$ & & & \\
\hline 7 & & $n_{1}=1000 \mathrm{~min}^{-1}$ & & \multirow{3}{*}{ B; UN } & \\
\hline 8 & & $n_{l}=1500 \mathrm{~min}^{-1}$ & & & \multirow[b]{2}{*}{ T, NUN } \\
\hline 9 & & $n_{l}=2000 \mathrm{~min}^{-1}$ & & & \\
\hline 10 & \multirow{9}{*}{ AL bronze } & $i=10$ & \multirow{4}{*}{$\mathbf{H}$; NUN } & \multirow{4}{*}{$\mathbf{H}$; NUN } & \multirow{4}{*}{$\mathbf{T}, \mathbf{H}, \mathrm{NUN}$} \\
\hline 11 & & $i=20$ & & & \\
\hline 12 & & $i=30$ & & & \\
\hline 13 & & $i=40$ & & & \\
\hline 14 & & $n_{1}=200 \mathrm{~min}^{-1}$ & \multirow{2}{*}{ P, NUN } & \multirow{2}{*}{$\mathbf{P}, \mathrm{NUN}$} & $\mathbf{P}, \mathrm{NUN}$ \\
\hline 15 & & $n_{l}=500 \mathrm{~min}^{-1}$ & & & \multirow{2}{*}{ H, NUN } \\
\hline 16 & & $n_{l}=1000 \mathrm{~min}^{-1}$ & \multirow{3}{*}{$\mathbf{H}, \mathrm{NUN}$} & \multirow{3}{*}{ H, NUN } & \\
\hline 17 & & $n_{l}=1500 \mathrm{~min}^{-1}$ & & & $\mathbf{H}, \mathbf{T}, \mathrm{NUN}$ \\
\hline 18 & & $n_{l}=2000 \mathrm{~min}^{-1}$ & & & $\mathbf{T}, \mathrm{NUN}$ \\
\hline 19 & \multirow{9}{*}{$\begin{array}{l}\text { Ductile } \\
\text { iron }\end{array}$} & $i=10$ & \multirow{4}{*}{$\mathbf{H} ; \approx \mathrm{UN}$} & \multirow{4}{*}{$\mathbf{B}, \mathbf{H}$} & \multirow{4}{*}{$\mathbf{T}, \mathbf{B}, \mathrm{NUN}$} \\
\hline 20 & & $i=20$ & & & \\
\hline 21 & & $i=30$ & & & \\
\hline 22 & & $i=40$ & & & \\
\hline 23 & & $n_{1}=200 \mathrm{~min}^{-1}$ & \multirow{5}{*}{$\mathbf{H}$; UN } & \multirow{5}{*}{$\mathbf{B}, \mathbf{H}, \approx \mathrm{UN}$} & \multirow{3}{*}{ B, NUN } \\
\hline 24 & & $n_{1}=500 \mathrm{~min}^{-1}$ & & & \\
\hline 25 & & $n_{l}=1000 \mathrm{~min}^{-1}$ & & & \\
\hline 26 & & $n_{I}=1500 \mathrm{~min}^{-1}$ & & & B, T, NUN \\
\hline 27 & & $n_{1}=2000 \mathrm{~min}^{-1}$ & & & T, NUN \\
\hline
\end{tabular}

\subsection{Transmission a-250}

The calculation results of load capacity of drive a-250 $(a=250 \mathrm{~mm})$ are given in the diagram figure 3.

For drive a-250 with worm made of alloy steel and worm gear from tin bronze CuSn12C-GZ can be seen that, on average, have about the same on one side load capacity for pitting compared with thermal stability $\left(T_{2}=6.400 \mathrm{Nm}\right)$ and on other side load capacity for wear comparing to the tooth root safety $\left(T_{2}=19.400 \mathrm{Nm}\right)$.

For a-250 with a worm made of alloy steel and worm gear of Al-bronze CuAl10Fe5Ni5 $\mathrm{C}-\mathrm{GZ}$ can be seen that with varying transmission ratio and varying speeds according to all criteria calculation results in not uniform load capacity.

For drive a-250 with a worm made of alloy steel and worm gear made of ductile iron EN-GJS-400-15 can be seen that for varying the transmission ratio the load capacity of drive is about the same compared the safety factor temperature of the drive with pitting safety $\left(T_{2} \approx 6.240 \mathrm{Nm}\right)$. 


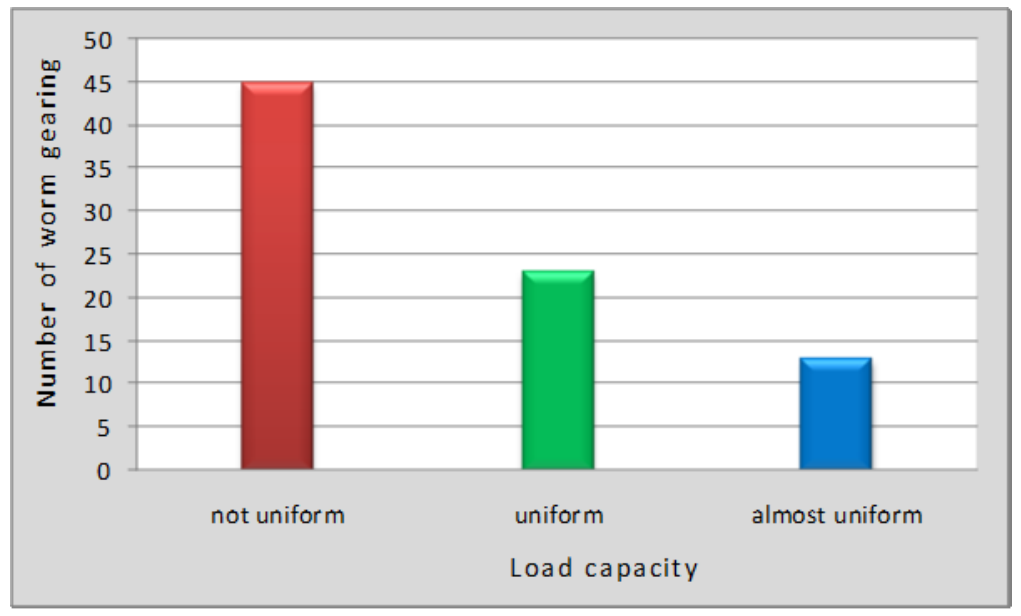

Fig. 4. Load capacity of transmission.

Calculation is performed for 81 cases which take into account the variation of the transmission ratio, speeds, material of worm gear and the axial distance. Above analysis (Table 2) shows the load capacity for different load capacity limitations. It may be noted that the largest load capacity of worm gear drives is calculated for wear, pitting and thermal stability.

From the aspect of use of available resources worm drives is very important that the drive has a similar load capacity for all limit states. This is indicated in the analysis as uniform (UN) or the not uniform load capacity (NUN).

From 81 calculations, only at 23 drives have uniform load capacity, 13 approximately uniform, while 45 drives have a not uniform load capacity (Fig. 4). The best use of resources of drives was obtained in the calculation with worm gear made of tin bronze. This is the reasons why majority of producers of worm gear drives use combination of material worm made of tempered (hardened) steel with ground teeth and worm gear of centrifugally cast tin bronze.

\section{Conclusion}

In this paper is presented calculation of load capacity for wear, pitting, fracture at the tooth root and thermal stability for selected family of worm gear drives with axial distance $a=63 \mathrm{~mm}, a=100 \mathrm{~mm}$ and $a=250 \mathrm{~mm}$. In calculation are varied the following parameters: axial distance, transmission ratio, speed, worm gear material, type and method of lubrication oil. Based on the calculation results can be conclude following:

- Results of the calculation (Table 2) show that the largest load capacity of worm gear drive for wear, pitting and thermal stability.

- From the aspect of use of available resources of worm gear drives is very important that the drive has a similar load capacity for all limitations.

- The results of analysis are shown in Table 2 and in Fig. 4 show that of the 81 analysed drives only 23 drives have uniform load capacity, in 13 is approximately uniform, while 45 have not uniform load capacity. Therefore, the maximum use of available resources was achieved in 23 drives ( $28 \%$ of all analysed drives).

This approach shows that the variation of parameters have decisive importance for load capacity of worm gears as well as the extension of working life. Small changes in the parameters can lead to significant savings which is good approach for product development engineers. 


\section{References}

1. B-R. Höhn, K. Michaelis, C. Weisel, International Conference on Gears - Gears 2010. VDI Berichte 2108.2 (2010)

2. A. Miltenović, M. Milovančević, Đ. Miltenović, Proceedings of the $5^{\text {th }}$ KOD, Novi Sad, Serbia (2008)

3. Đ. Miltenović, M. Tica, A. Miltenović, M. Banić, Proceedings of the $12^{\text {th }}$ DEMI, Banja Luka, $\mathrm{BiH}(2015)$

4. Đ. Miltenović, Istraživanje termičke stabilnosti i habanja pužnih prenosnika ( $\mathrm{PhD}$, Banja Luka, 2017)

5. V. Miltenović, M. Banić, A. Miltenović, Proceedings of the $7^{\text {th }}$ KOD 2012, Balatonfured, Hungary (2012)

6. DIN 3996: Tragfähigkeitsberechnung von Zylinder-Schneckengetrieben mit sich rechtwinklig kreuzenden Achsen (2012) 